This document is the unedited author's version of a submitted work that was subsequently accepted for publication in Energy \& Fuels, (C) American Chemical Society, after peer review. To access the final edited and published work see:

Várhegyi, G. Empirical models with constant and variable activation energy for biomass pyrolysis. Energy \& Fuels 2019, 33, 2348-2358.

doi: $10.1021 /$ acs.energyfuels. 9 b00040

\title{
Empirical Models with Constant and Variable Activation Energy for Biomass Pyrolysis
}

\section{Gábor Várhegyi, ${ }^{*}$}

Institute of Materials and Environmental Chemistry, Research Centre for Natural Sciences, Hungarian Academy of Sciences, PO. Box 286, Budapest, 1519 Hungary

KEYWORDS: Least Squares; Isoconversional; Model-free; Kinetics; Non-isothermal; Biomass; Wood; Bark; Agricultural wastes.

\begin{abstract}
The so called "model-free" or isoconversional way of kinetic modelling was examined. In this field the available evaluation methods do not aim at an optimal fit for the experimental data. In the present work the functions of the corresponding kinetic equation were approximated by simple versatile formulas; the number of the unknown parameters was kept on reasonably low levels; and the evaluation aimed at the best fit for the experiments by the method of least squares. The considerations and methods were tested on 85 thermogravimetric (TGA) experiments which had been published earlier with different types of kinetic modelling. The experiments belonged to 16 biomass samples including woody biomass, agricultural residues and industrial wastes. The temperature programs comprised constant heating rates, stepwise heating, constant reaction rate heating (CRR), isothermal temperature programs, and a modulated temperature program. The evaluations were based on four to nine experiments for each sample. The best fit was searched for the mass loss rate curves because they reflect better the peculiarities of the pyrolysis than the integral curves. An empirical model with variable activation energy provided good fit for all experimental data. It described the experiments of a biomass sample by 11 parameters. Another model with constant $E$ values provided rougher, but still usable approximations for the data. It allows fast numerical solutions that may be helpful in complex modelling tasks. Both models described the experiments at a variety of temperature programs by a given set of model parameters.
\end{abstract}




\section{INTRODUCTION}

The kinetics of the biomass pyrolysis is usually based on models that are built of equations of type $\mathrm{d} \alpha / \mathrm{dt}=\mathrm{A} \exp (-\mathrm{E} / \mathrm{RT}) \mathrm{f}(\alpha)$

where $\alpha$ is a reacted fraction (conversion), $E$ is the apparent activation energy, and $A$ is the preexponential factor. Obviously more than one such equation is needed when the model reflects the complexity of the biomass pyrolysis reactions. In such cases $\alpha$ refers only to a part of the sample. If distributed activation energy models are employed, then an infinite number of reactions are assumed with an infinite number $\alpha$ conversions.

An entirely different approach is when only one equation of type 1 is assumed with varying $\mathrm{E}$ and A:

$$
\mathrm{d} \alpha / \mathrm{dt}=\mathrm{A}(\alpha) \mathrm{f}(\alpha) \exp (-\mathrm{E}(\alpha) / \mathrm{RT})
$$

Here $A(\alpha), f(\alpha)$, and $E(\alpha)$ are empirical functions. Obviously only the product of $A(\alpha)$ and $f(\alpha)$ can be determined from the experimental data. More precisely, an empirical $[A(\alpha) f(\alpha)]$ function can be factored to an $A(\alpha)$ and an $f(\alpha)$ part in an infinite number of ways.

For historical reason the kinetic evaluations by eq 2 are frequently called "model-free" methods. This term is misleading since eq 2 itself is a model. ${ }^{1}$ It is more precise to call eq 2 "isoconversional" which means that the reaction rate, $\mathrm{d} \alpha / \mathrm{dt}$, is a function of the temperature only at any selected $\alpha$ value and does not depend on the temperature history that led to a given $(\alpha, T)$ point. ${ }^{1}$ This definition, and eq 2 itself can only be approximatively true for biomass materials because they have complicated reactions, and the temperature history may affect the importance of the various partial reactions in the overall decomposition.

The literature of the "model-free" or isoconversional evaluations is huge. About 4000 scientific papers contain the characteristic terms of these methods in the Web of Science database. ${ }^{2}$ The present paper is restricted to the kinetic studies on biomass pyrolysis, where the isoconversional methods have been present for nearly 40 years. ${ }^{3}$ According to the Web of Science, more isoconversional evaluations are reported in the literature of biomass pyrolysis than all other methods combined. A recent review and case study deals with the isoconversional kinetics of lignocellulosic materials. ${ }^{4}$ Its treatment includes a concise description of the most important evaluation techniques emphasizing their advantages and disadvantages and giving ample references from 1956 till the present.

Eq 2 is usually employed for thermogravimetric (TGA) and differential scanning calorimetric (DSC) experiments. Nevertheless, it may be employed for any experimental technique which provides the reacted fraction / conversion of either the whole sample or a given species while the temperature of the sample is measured with an adequate precision. (Here the term "adequate" depends obviously on the sensitivity of the model and the evaluation method to the experimental errors.)

Several factors led to the writing of the present work. One of them was that I see questions and problems with this type of research, as outlined below. Another factor was the high number of the publications with isoconversional kinetics; I wished to contribute to the analysis of their reliability. Besides, the potential of eq 2 as a relatively simple empirical model is also interesting. ${ }^{5-8}$

One of the open questions with the isoconversional evaluations is the high number of the parameters which are derived from a few, rather similar TGA curves. Though there are evaluation methods that can be carried out at any $\mathrm{T}(\mathrm{t})$ temperature programs, ${ }^{1,4}$ practically all studies in the field are based on constant heating rate experiments only. The Kinetics Committee of the International Confederation for Thermal Analysis and Calorimetry (ICTAC) recommends carrying out the evaluation at $9-19$ fixed $\alpha$ values: "It is recommended to determine the $\mathrm{E}_{\alpha}$ values in a wide range of $\alpha=0.05-0.95$ with a step of not larger than 0.05 and to report the resulting dependencies of $E_{\alpha}$ vs. $\alpha . " 1$ (Here $E_{\alpha}$ is a shorthand for $\mathrm{E}(\alpha)$ ). Keeping in 
mind that there is a $[A(\alpha) f(\alpha)]$ value for each $E_{\alpha}$, the total number of the unknowns in a typical isoconversional evaluation is $9 \times 2-19 \times 2$. However, higher number of unknown parameters are also determined in the isoconversional studies. For example, Samuelsson et al. determined $23 \times 2$ parameters from 10 constant heating rates experiments ${ }^{5}$ while Carrier et al. presented $E-\alpha$ figures with $41 E_{\alpha}$ values using four heating rates. ${ }^{9}$ Naqvi et al. presented $39 \times 2$ parameters in a detailed table that were determined from three constant heating rate experiments. ${ }^{10}$

During my work in various teams for 30 years we realized that the simultaneous evaluation of linear and non-linear temperature programs increases the information of the series of TGA experiments, ${ }^{11-17}$ and kinetic models with 12-13 adjustable parameters were sufficient for fitting such series of experiments by the method of least squares for the pyrolysis of a wide variation of biomass samples. ${ }^{13,14,16,17}$ (Models assuming pseudo-components and parallel reactions were employed in these works.) Moreover, the number of parameters could be decreased further by assuming partly common kinetic parameters for different biomass samples. ${ }^{14-17}$ Here the question arises: If 13 parameters are enough for a good fit then why should anyone determine $19 \times 2$ or $39 \times 2$ parameters? Are the obtained parameters just redundant or do they serve for averaging out the experimental errors in their further processing? In the latter case why not a true least squares evaluation is chosen for averaging out the experimental errors via a curve fitting?

Another question is the large variation of activation energies in the literature of the isoconversional studies. In the case of biomass pyrolysis kinetics $E_{\alpha}$ values as high as 1070 and $1327 \mathrm{~kJ} / \mathrm{mol}$ were reported. ${ }^{18,10}$ Unrealistically low $E_{\alpha}$ values also arose, for example $10-12 \mathrm{~kJ} / \mathrm{mol}^{10,19}$ (We shall turn back to the meaning of the term "unrealistic $E$ " in the article.) Several causes may be assumed here, among others: (i) Eq 2 is not suitable for the description of the given pyrolysis process with realistic $E_{\alpha}$ values; (ii) The evaluation method is too sensitive to the experimental errors; (iii) Eq 2 itself is ill-conditioned, meaning that a small error in the initial data can result in much larger errors in the results whatever evaluation method is employed. The present work aims at the clarification of the above questions.

The available "model-free" evaluation methods appear to be arbitrary and sensitive to the experimental errors. Here the term "arbitrary" means that their elaboration aimed at relatively simple procedures instead of finding the best fit between the predicted values and the observed data. I think there is no need for such simplifications in the $21^{\text {th }}$ century due to the high development of the computers and computing methods. In other areas of the sciences the usual way of the evaluation is to find the best fit between the predicted and the observed data by the method of least squares. The use of this approach for isoconversional evaluations is a main goal in the present work.

\section{SAMPLES AND METHODS}

2.1 Samples and Experiments. The considerations of the present work were tested by evaluating TGA experiments that had been evaluated earlier by other models and appeared in six publications in Energy \& Fuels. $^{12-17} 85$ TGA experiments were reevaluated in the present paper. They belonged to 16 biomass samples which comprised woody biomasses, ${ }^{12,16,17}$ agricultural residues, ${ }^{14,15}$ and industrial wastes. ${ }^{13}$ The temperature programs included constant heating rates, stepwise heating, constant reaction rate heating (CRR), isothermal temperature programs, and a modulated temperature program. There were $4-9$ experiments with for each biomass sample. The list of the samples and the TGA experiments belonging to them is given in Subsection 4.3. Figure 1 displays the temperature programs employed in the work of Tapasvi et al. The corresponding figures for the other samples are given in the Supporting Information. Four different TGA apparatuses were involved in the studies. Emphasis was given to ensure a true kinetic 
regime by employing small sample masses and considering that very small sample masses are needed at higher heating rates (because the peak height of the mass loss rate curves is roughly proportional to the heating rate). ${ }^{12-17}$

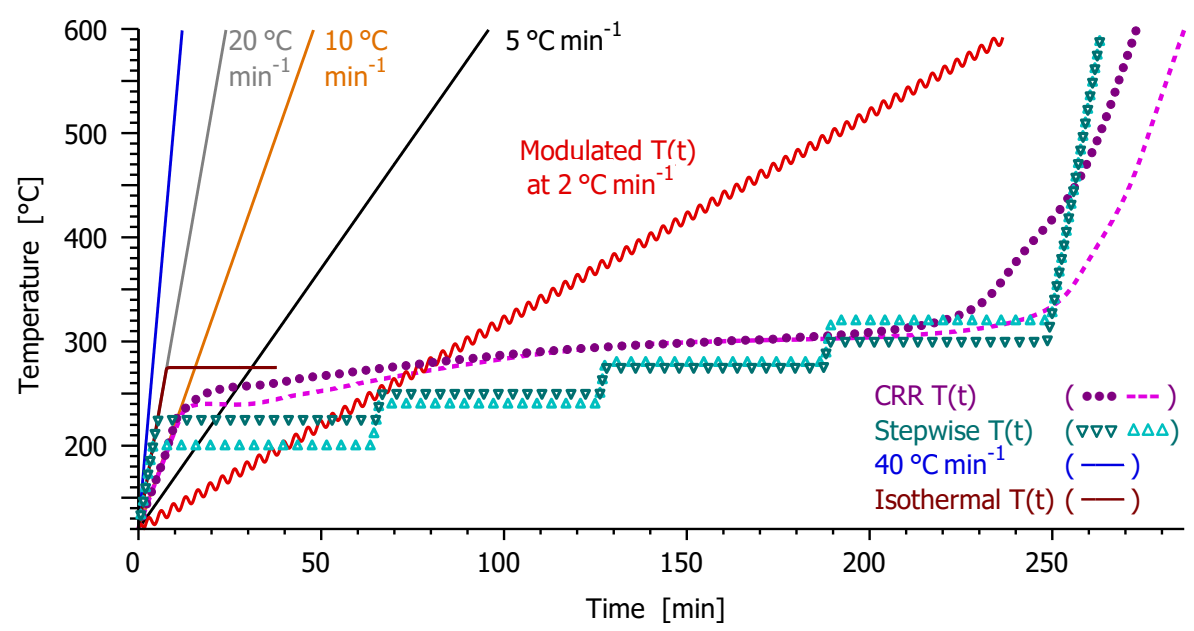

Figure 1. Temperature programs used in the TGA experiments of Tapasvi et al. ${ }^{16}$

2.2. Evaluation by the Method of Least Squares and Characterization of the Fit Quality. Such values were searched for the unknown model parameters that minimize the difference between the experimental $\left(X^{\mathrm{obs}}\right)$ and the predicted $\left(X^{\mathrm{calc}}\right)$ data:

$$
\text { of }=\sum_{j=1}^{N_{\text {exper }}} \sum_{i=1}^{N_{j}} w_{j}\left[X_{j}^{o b s}\left(t_{i}\right)-X_{j}^{\text {calc }}\left(t_{i}\right)\right]^{2}
$$

Here $o f$ is the objective function to be minimized; $N_{\text {exper }}$ is the number of experiments evaluated together; $N_{\mathrm{j}}$ is the number of $t_{\mathrm{i}}$ time values in experiment $j$; and the $w_{\mathrm{j}}$ weight factors express the different uncertainties of the different experimental curves. In the case of TGA experiments eq 3 may aim at an optimal fit either on the normalized sample mass, $m^{\mathrm{obs}}(t)$, or on its derivative. The latter is more characteristic for biomass pyrolysis; we fitted the $-d m^{\text {obs }} / d t$ curves in nearly all of our works since $1989 .{ }^{20}$ In this case the objective function is

$$
o f=\sum_{j=1}^{N_{\text {exper }}} \sum_{i=1}^{N_{j}} \frac{\left[\left(\frac{d m}{d t}\right)_{j}^{o b s}\left(t_{i}\right)-\left(\frac{d m}{d t}\right)_{j}^{c a l c}\left(t_{i}\right)\right]^{2}}{N_{j} h_{j}^{2}}
$$

Here $m$ is the sample mass normalized by the initial dry sample mass. The division by $h_{j}^{2}$ serves to counterbalance the high magnitude differences. Traditionally $h_{\mathrm{j}}$ is the highest observed value of the given experiment:

$$
h_{\mathrm{j}}=\max \left(\frac{d m}{d t}\right)_{j}^{o b s}
$$

The normalization by the highest observed values in the least squares sum assumes implicitly that the relative precision is roughly the same for the different experiments. This assumption has proved to be useful in numerous works on non-isothermal kinetics since $1993 .^{21}$

The obtained fit quality can be characterized separately for each of the experiments evaluated together. For this purpose, the relative deviation (reldev, \%) will be used. The root mean square (rms) difference between the observed and calculated values is expressed as percent of peak maximum. For experiment $j$ we get: 
$\operatorname{reldev}(\%)=100\left\{\sum_{i=1}^{N_{j}} \frac{\left[\left(\frac{d m}{d t}\right)_{j}^{o b s}\left(t_{i}\right)-\left(\frac{d m}{d t}\right)_{j}^{c a l c}\left(t_{i}\right)\right]^{2}}{N_{j} h_{j}^{2}}\right\}^{0.5}$

The fit quality for a given group of experiments is characterized by the root mean square of the corresponding relative deviations. For example, the root mean square reldev on all the 85 experiments of this study is denoted by reldev 85 .

Section 5 deals with the least squares curve fitting for other experimental quantities.

2.3. Computational Methods. Simple, but safe numerical methods were selected similarly to our previous works. ${ }^{11-17,20-22}$ The experimental temperature values were connected by linear interpolation and the kinetic differential equation (eq 2) was solved by an adaptive stepwise Runge-Kutta method ${ }^{23}$ for each experiment in each $\left[\mathrm{t}_{\mathrm{i}-1}, \mathrm{t}_{\mathrm{i}}\right]$ interval. (The forms of the $E(\alpha)$ and $A(\alpha) f(\alpha)$ functions considered in this work are shown in Subsections 3.1-3.2.)

The minimization of the objective function was carried out by a variant of the Hook-Jeeves method. The Hook-Jeeves method is a slow but simple and dependable direct search algorithm. ${ }^{24}$ The original algorithm was supplemented by a parabolic interpolation for finding the optimal step sizes. The safety and the speed of the convergence were enhanced by simple parameter transformations which are outlined after the setup of the model, in Subsection 3.2. The scaling of the parameters to similar magnitudes may also be helpful in the direct search method. The Supporting Information contains 32 sets of model parameters that an interested reader may use in his/her own calculations as initial values. It is possible to start the optimization from the results of a plain first order kinetic evaluation, too.

The experimental $-d m / d t$ values were obtained by approximating the measured $m(t)$ values by smoothing splines. $^{25}$ The root mean square difference between the original $m(t)$ and the smoothing spline were typically much below $1 \mu \mathrm{g}$. Such a small difference does not introduce considerable systematic errors into the least-squares kinetic evaluations. ${ }^{22}$

Fortran 2003 and $\mathrm{C}++$ programs were used for the numerical calculations and for graphics handling, respectively.

2.4. Automation. The present work was based on around 1000 least squares evaluations of which 556 proved to be useful for the tables and figures of this article and its Supporting Information. 16 experimental series were evaluated in 34 ways, as described in Section 4, and a few additional evaluations were needed for Section 5. Obviously, some automation was needed for so many evaluations. The calculations were organized by batch files. The user dialogues of the evaluation programs were recorded in text files which were read together with the experimental data by the programs at each evaluation. The evaluation programs generated several thousand graphical and textual output files that were collected and arranged by small script programs so that they could be surveyed within reasonable amounts of time.

\section{EMPIRICAL FUNCTIONS FOR THE MODELLING}

3.1. Formulation. As outlined in the Introduction, the $E(\alpha)$ és $A(\alpha) f(\alpha)$ functions are approximated by simple formulas so that the resulting empirical model would contain only a limited number of parameters and the evaluation could be carried out by the method of least squares. This is the topic of the present section.

$E(\alpha)$ and $A(\alpha) f(\alpha)$ can be arbitrary functions with positive values in the domain $0 \leq \alpha<1$ in eq $2 . A(\alpha) f(\alpha)$ must be zero at $\alpha=1$ because only a zero value ensures mathematically the termination of the process. To 
make the fulfillment of this requirement easier we shall introduce an $(1-\alpha)$ factor into $A(\alpha) f(\alpha)$ and write eq 2 as follows:

$$
\mathrm{d} \alpha / \mathrm{dt}=\tilde{\mathrm{A}}(\alpha)(1-\alpha) \exp (-\mathrm{E}(\alpha) / \mathrm{RT})
$$

Here $\tilde{A}(\alpha)$ is $A(\alpha) f(\alpha) /(1-\alpha)$ when $\alpha<1$. The division by $(1-\alpha)$ is not possible at the $\alpha=1$ point, but $\tilde{A}(\alpha)$ can have any finite value there. Note that the appearance of (1- $\alpha)$ in eq 7 does not mean the assumption of a first-order kinetics; it serves only to for a convenient treatment.

Taking the logarithm of $\tilde{A}(\alpha)$ and rearranging eq 7 we get:

$$
\mathrm{d} \alpha / \mathrm{dt}=(1-\alpha) \exp (\ln \tilde{\mathrm{A}}(\alpha)-\mathrm{E}(\alpha) / \mathrm{RT})
$$

When taking a logarithm, one must assume that the argument does not take zero values. This is not a strong assumption, however, because $\tilde{A}(\alpha)$ may have arbitrarily small positive values. For example, the lowest $\tilde{A}(\alpha)$ value in the test evaluations of this work was around $10^{-72}$ at $\alpha=1$.

The next step of the work is to introduce straightforward approximations for $\ln \tilde{A}(\alpha)$ and $E(\alpha)$. A general and widespread way for function approximations is the use of polynomials because they have simple form; their handling is easy; and they can approximate a wide range of functions. Accordingly, polynomials up to fifth order will be used in this work.

3.2. Simple Parameter Transformations for a Safer Optimization. Elementary mathematical operations will be given here which enhance the safety and the speed of the convergence during the minimization of the lest squares sum. They aim at decreasing the interrelations (compensation effects) between the parameters in the evaluation process. The first step is to map the domain of the polynomials from $[0,1]$ to $[-1,1]$. For this a variable $x$ is introduced:

$$
\mathrm{x}=2 \alpha-1
$$

The polynomials describing $E$ and $\ln \tilde{A}$ will be written as functions of $x$ :

$$
\begin{aligned}
& \mathrm{E}(\alpha)=\mathrm{a}_{0}+\mathrm{a}_{1} \mathrm{x}+\mathrm{a}_{2} \mathrm{x}^{2}+\mathrm{a}_{3} \mathrm{x}^{3}+\mathrm{a}_{4} \mathrm{x}^{4}+\mathrm{a}_{5} \mathrm{x}^{5} \\
& \ln \tilde{\mathrm{A}}(\alpha)=\mathrm{b}_{0}+\mathrm{b}_{1} \mathrm{x}+\mathrm{b}_{2} \mathrm{x}^{2}+\mathrm{b}_{3} \mathrm{x}^{3}+\mathrm{b}_{4} \mathrm{x}^{4}+\mathrm{b}_{5} \mathrm{x}^{5}
\end{aligned}
$$

An example for the usefulness of this mapping: The $\alpha^{4}$ and $\alpha^{5}$ values are close to each other in domain $[0,1]$, hence their coefficients can compensate each other a bit during the minimization. On the other hand, $x^{4}$ and $x^{5}$ differ very much at negative $\mathrm{x}$ values hence their coefficients cannot compensate each other. A further, optional step in this direction is the use of the Chebyshev polynomials of the first kind due to their favorable properties. ${ }^{23}$ An identical rearrangement of equations 10 and 11 yields

$$
\begin{aligned}
& \mathrm{E}(\alpha)=\bar{a}_{0}+\overline{\mathrm{a}}_{1} \mathrm{~T}_{1}(\mathrm{x})+\overline{\mathrm{a}}_{2} \mathrm{~T}_{2}(\mathrm{x})+\overline{\mathrm{a}}_{3} \mathrm{~T}_{3}(\mathrm{x})+\overline{\mathrm{a}}_{4} \mathrm{~T}_{4}(\mathrm{x})+\overline{\mathrm{a}}_{5} \mathrm{~T}_{5}(\mathrm{x}) \\
& \ln \tilde{\mathrm{A}}(\alpha)=\overline{\mathrm{b}}_{0}+\overline{\mathrm{b}}_{1} \mathrm{~T}_{1}(\mathrm{x})+\overline{\mathrm{b}}_{2} \mathrm{~T}_{2}(\mathrm{x})+\overline{\mathrm{b}}_{3} \mathrm{~T}_{3}(\mathrm{x})+\overline{\mathrm{b}}_{4} \mathrm{~T}_{4}(\mathrm{x})+\overline{\mathrm{b}}_{5} \mathrm{~T}_{5}(\mathrm{x})
\end{aligned}
$$

where $T_{1} \ldots T_{5}$ are the Chebyshev polynomials of the first kind, ${ }^{23}$ while $\bar{a}$ and $\bar{b}$ are coefficients to be determined during the minimization of the objective function. Note that the calculations with the Chebyshev polynomials of the first kind is fast and easy through their well-known recurrence relations. ${ }^{23}$ (The evaluation of the $T_{1} \ldots T_{5}$ polynomials at any $x$ can be carried out through a few simple program lines.) The results can be transformed back to the form of equations 10 and 11 for reports and publications. The models given in the Supporting Information are presented in both formats.

Another elementary parameter transformation serves to decrease the interrelation between the preexponential factor and the activation energy during the minimization. ${ }^{26}$ At constant $A$ and $E$ it can be carried out by minimizing a transformed variable $Z$ instead of $A$ : 
$\mathrm{Z}=\ln \mathrm{A}-\mathrm{E} / \mathrm{RT}_{\mathrm{m}}$

where $T_{\mathrm{m}}$ is arbitrarily chosen fixed temperature somewhere in the middle of the temperature interval. ${ }^{26}$ This method can be employed for $\tilde{A}(\alpha)$ and $E(\alpha)$, too, by substituting equations 12 and 13 (or equations 10 and 11) into the place of $E$ and $\ln A$ in equation 14. Then the coefficients of the resulting $Z$ polynomial are determined together with the coefficients of the $E$ polynomial.

3.3. Scale Factors. The solution of eq 2 yields the calculated $\alpha$ and $d \alpha / d t$ values. It would be straightforward to compare them to the experimental $\alpha$ or $d \alpha / d t$ points by the method of least squares. This topic will be treated in Section 5. The correct determination of the experimental $\alpha(t)$ values is problematic because the thermal decomposition of the biomass materials continues to very high temperatures by the slow carbonization of chars. ${ }^{27}$ Part of the pyrolysis reactions overlap more or less with the charring of the residues, especially when the sample contains a considerable amount of lignin. Accordingly, $\alpha^{\text {exp }}$ can only be determined approximately. We shall turn back to this point in Section 5.

Herewith a simpler approach is employed: $d m^{\text {calc }} / d t$ is obtained from $d \alpha^{\text {calc }} / d t$ by a multiplication:

$$
d m^{\mathrm{calc}} / d t=\mathrm{c} d \alpha^{\mathrm{calc}} / d t
$$

where $c$ is a scale factor to be determined during the evaluation. $c$ is equal to the amount of volatiles forming from a unit mass of the sample by the model. Hence 1-c is the char yield predicted by the model.

Three options will be considered for the determination of $c$ :

(1) A separate $c_{\mathrm{j}}$ value is assumed for each experiment and the $c_{\mathrm{j}}$ values are determined together with the other model parameters in the least squares evaluation. Disadvantage: this approach highly increases the number of parameters in the model.

(2) A common $c$ value is assumed for all experiments. $c$ is determined together with the other model parameters in the least squares evaluation. Disadvantage: this is only an approximation because the char yield, 1-c, may depend on the temperature programs. ${ }^{27}$ However, this dependence is usually smaller than the baseline uncertainties of the apparatuses.

(3) A separate $c_{\mathrm{j}}$ value is assumed for each experiment and the $c_{\mathrm{j}}$ values are approximated by the experimental mass loss values in the domain of experiments. Disadvantages: (i) It is only approximation; (ii) It cannot be employed if the temperature programs are terminated without a heating to higher temperatures (like the isothermal experiments in Figure 1).

In the present work each of the above approaches were tested. The number of least squares evaluations were 224, 224 and 96 for methods (1), (2) and (3), respectively, as outlined in the next section. The results were roughly the same at each approach. The author's preference is method (2). The figures of the next section and the models and figures in the Supplementary Information were determined in that way, assuming a common $c$ for all experiments with a given sample.

\section{RESULTS AND DISCUSSION}

4.1. The Effects of the Polynomial Order on the Results. The experiments belonging to the 16 biomass samples have been evaluated by different ways. When $5^{\text {th }}$ order polynomial approximation was employed for both $E$ and $\ln \tilde{A}$, the model proved to be ill-conditioned. Four of the 16 samples yielded $E(\alpha)$ curves with negative values around $\alpha=1$ in that case, and two other samples produced $E$ values of $15-17 \mathrm{~kJ} / \mathrm{mol}$. To get rid of such meaningless $E$ values, the calculations were carried out with polynomials of lower order, too. The results are shown in Table 1. The first two columns show the orders of the polynomials tested. 
In each case all available experiments were evaluated by the method of least squares (eq 4) for the 16 biomass samples. Both methods (1) and (2) of the previous subsection were tested in these evaluations. Accordingly, the eight rows in Table 1 contain data that were obtained from $8 \times 16 \times 2$ least squares evaluations on altogether 85 TGA experiments. The results were characterized by calculating the root mean square of the relative deviations for the 85 experiments. The average, the lowest and the highest $E$ values are also displayed in each group.

\section{Table 1. Evaluations with Different Degrees of Polynomials ${ }^{a, b}$}

\begin{tabular}{cccccccccc}
\hline $\begin{array}{c}\text { Order of poly- } \\
\text { nomials for }\end{array}$ & \multicolumn{3}{c}{ Separate $c_{\mathrm{j}}$ for each experiment } & \multicolumn{3}{c}{ Common $c$ value for a sample } \\
$E(\alpha)$ & $\ln \tilde{A}(\alpha)$ & reldev85 & mean & lowest & highest & reldev85 & mean & lowest & highest \\
& & & $E$ & $E$ & $E$ & & $E$ & $E$ & $E$ \\
\hline 0 & 5 & 3.60 & 188 & 163 & 210 & 3.75 & 185 & 168 & 207 \\
1 & 5 & 3.44 & 190 & 127 & 266 & 3.63 & 190 & 130 & 268 \\
2 & 5 & 3.08 & 179 & 75 & 276 & 3.34 & 182 & 91 & 278 \\
3 & 5 & 2.72 & 184 & 67 & 408 & 2.97 & 185 & 63 & 469 \\
4 & 5 & 2.61 & 172 & -600 & 429 & 2.84 & 173 & -666 & 529 \\
5 & 5 & 2.55 & 178 & -347 & 395 & 2.76 & 180 & -76 & 408 \\
3 & 3 & 4.70 & 152 & -430 & 235 & 4.73 & 152 & -430 & 235 \\
4 & 4 & 3.06 & 158 & -736 & 364 & 3.08 & 157 & -733 & 360
\end{tabular}

a The experiments for 16 biomass samples were evaluated in different ways. reldev 85 is the root mean square relative deviation which was calculated for the 85 available experimental $-d m / d t$ curves at each type of evaluations. ${ }^{\mathbf{b}}$ The dimensions of $E$ and reldev $_{85}$ are $\mathrm{kJ} / \mathrm{mol}$ and $\%$.

The activation energies varied in reasonable ranges when $E(\alpha)$ was approximated by polynomials of 0 to 3 order and $\ln \tilde{A}(\alpha)$ was described by $5^{\text {th }}$ order polynomials. When the order of polynomials for $\ln \tilde{A}(\alpha)$ was decreased, unacceptable results were obtained, as the last two rows shows in Table 1.

Obviously, the fit qualities were the best when $5^{\text {th }}$ order polynomials were employed both for $E(\alpha)$ and $\ln \tilde{A}(\alpha)$ : reldev 85 values 2.55 and $2.66 \%$ were obtained then. It is possible to force the values of $E(\alpha)$ into preset limits by constraints during the minimization to avoid the meaningless activation energies. However, the use of $3^{\text {rd }}$ order polynomials for $E(\alpha)$ is much simpler than the use of constraints and the increase of the reldev 85 values was not substantial in this way, as the data in Table 1 shows. For $3^{\text {rd }}$ order $E(\alpha)$ polynomials the number of parameters is 11 if common $c$ values are used for the experiments of a biomass sample: four coefficients for $E$, and six coefficients for $\tilde{A}$, and a scale factor $c$. The fit quality and the curves calculated from this model variant are shown in Figure 2 and in the figures of the Supporting Information.

4.2. Approximations with Constant Activation Energies. The first line of data in Table 1 shows evaluations when $E$ did not depend on $\alpha$. They provided reasonable descriptions for the 85 experiments treated in this work. The fit quality is illustrated in Figure 2 and in further figures in the Supporting Information. The blue-colored curves belong to this approximation. If the $c$ scale factors are determined by the second method of Subsection 3.3 then the number of model parameters is 8: one $E$, six coefficients for $\tilde{A}$, and a scale factor, $c$. Four to nine experiments were available for each biomass sample hence the number of unknowns for an experiment varied between 0.9 and 2 in this type of evaluations. Therefore, the model parameters were based on an ample amount of experimental information. 


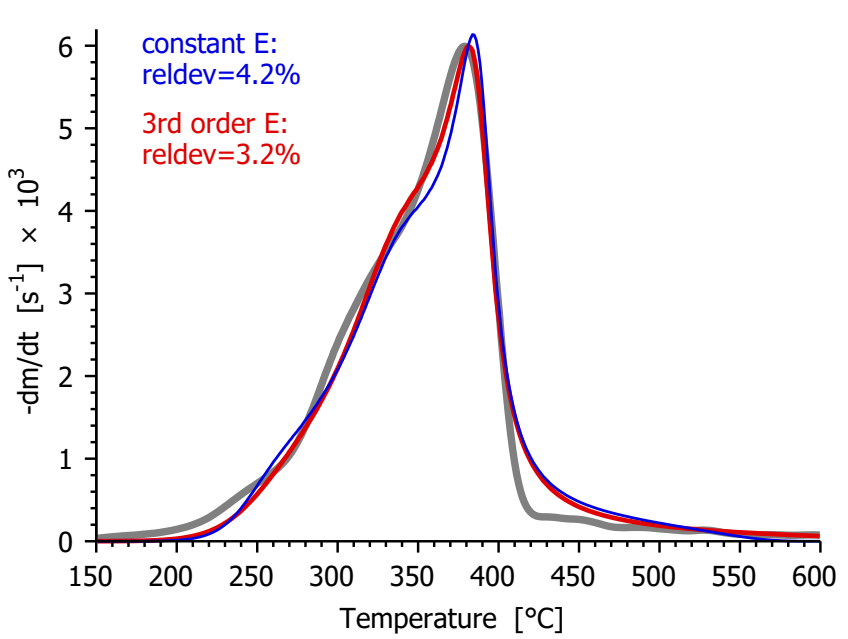

(a) Willow shoots, $40^{\circ} \mathrm{C} / \mathrm{min}$

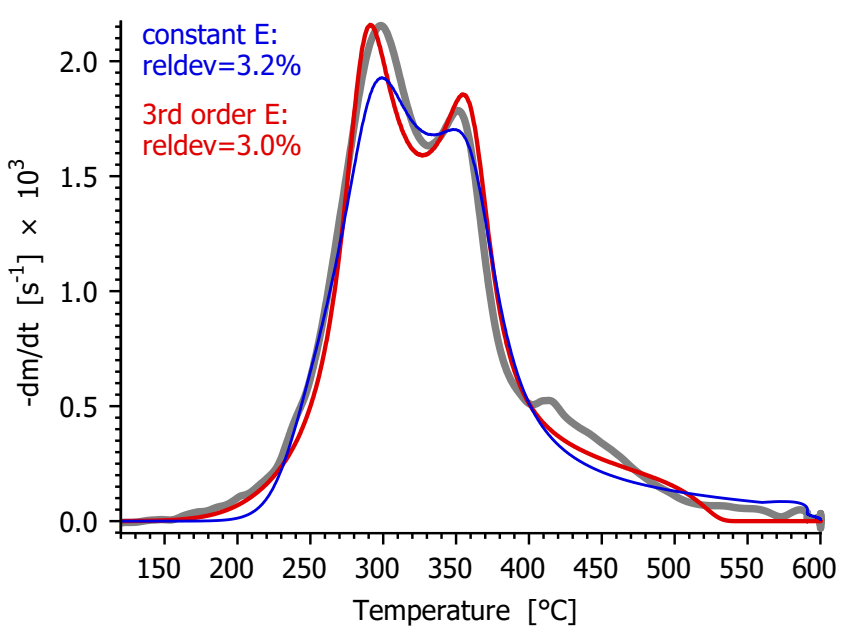

(c) Brewer spent grains, $20^{\circ} \mathrm{C} / \mathrm{min}$

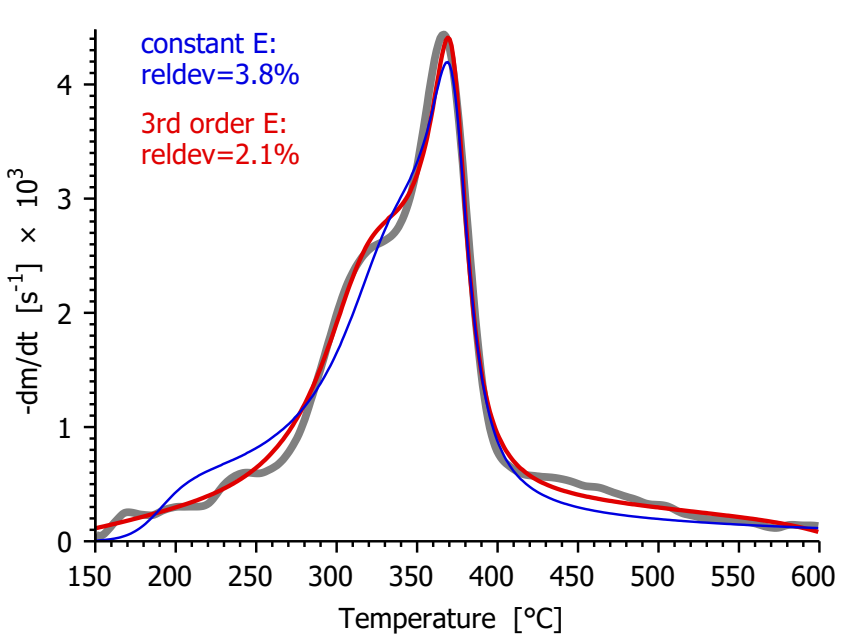

(e) Rice husk, $40^{\circ} \mathrm{C} / \mathrm{min}$

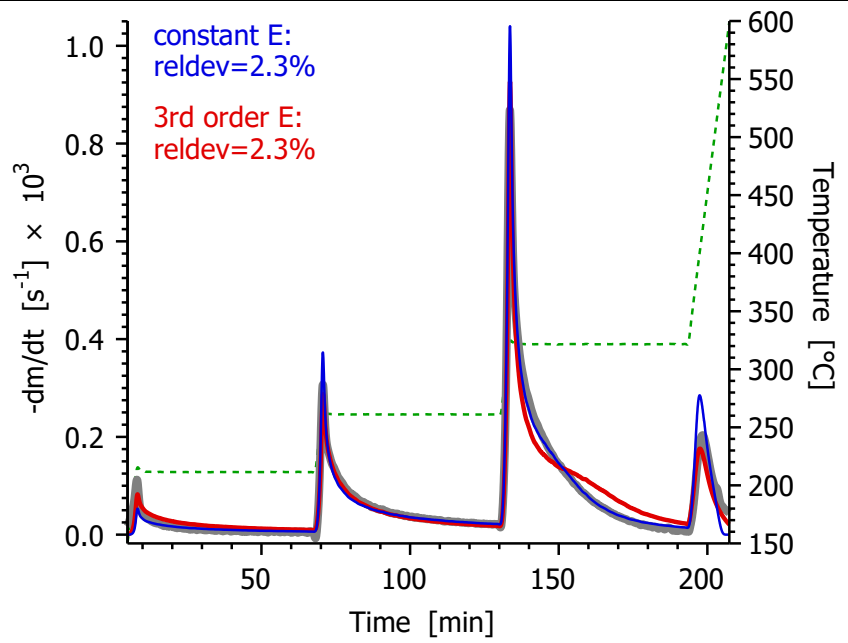

(b) Willow shoots, stepwise $T(t)$

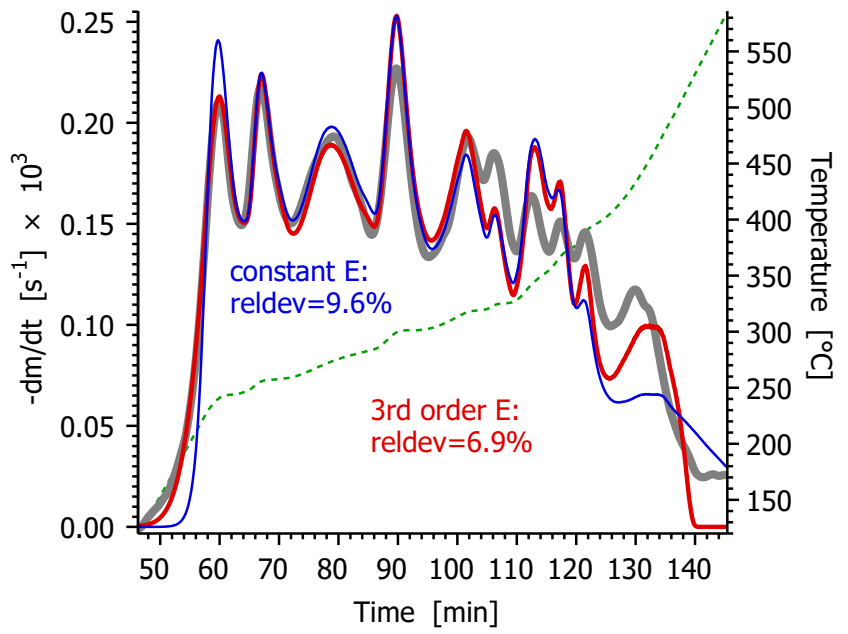

(d) Brewer spent grains, CRR T(t)

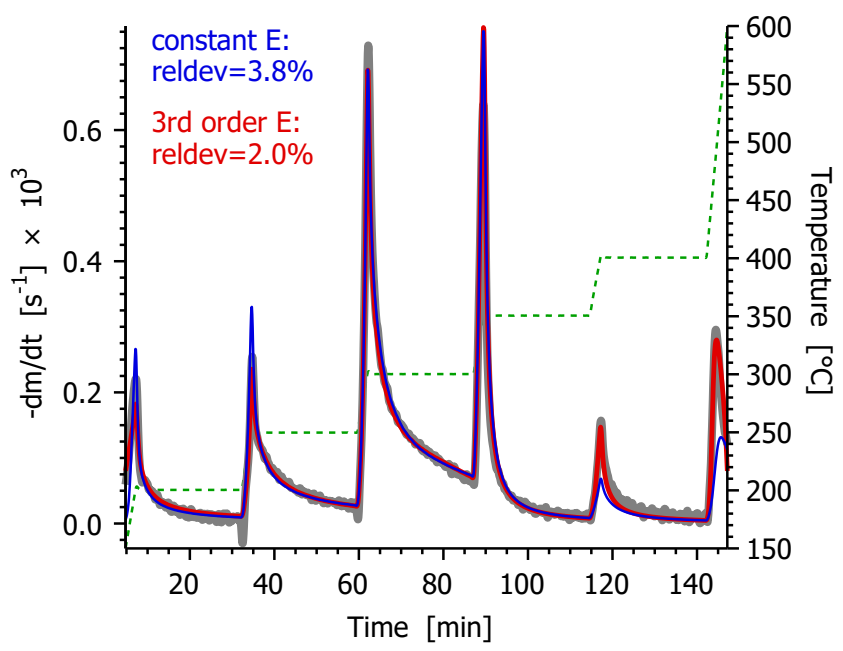

(f) Rice husk, stepwise $T(t)$ 


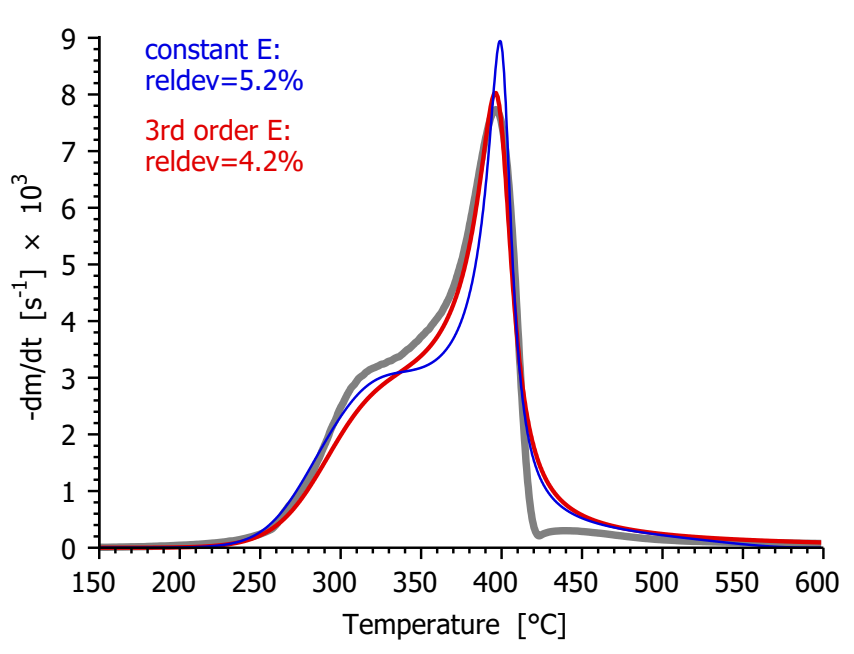

(g) Birch, $40^{\circ} \mathrm{C} / \mathrm{min}$

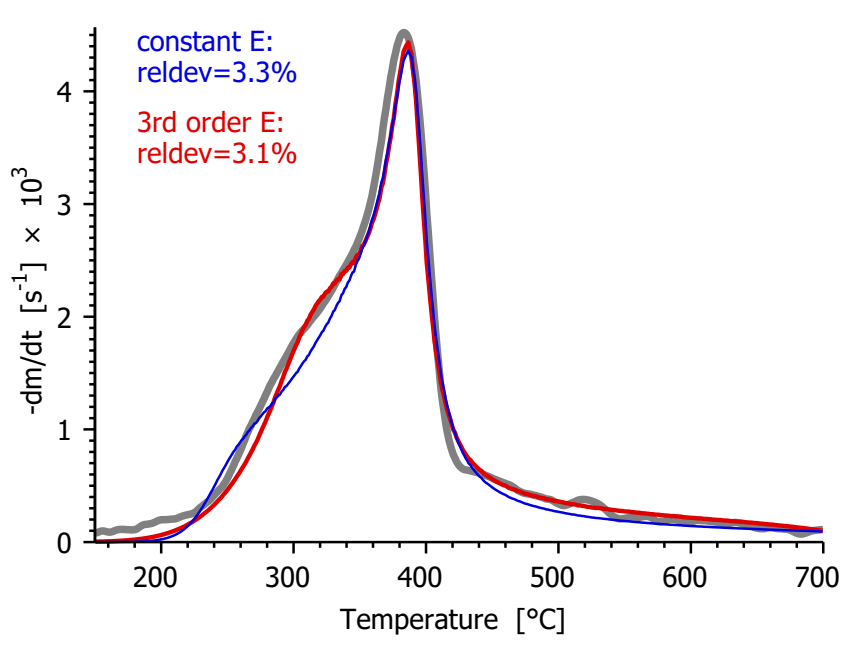

(i) Spruce bark, $40^{\circ} \mathrm{C} / \mathrm{min}$

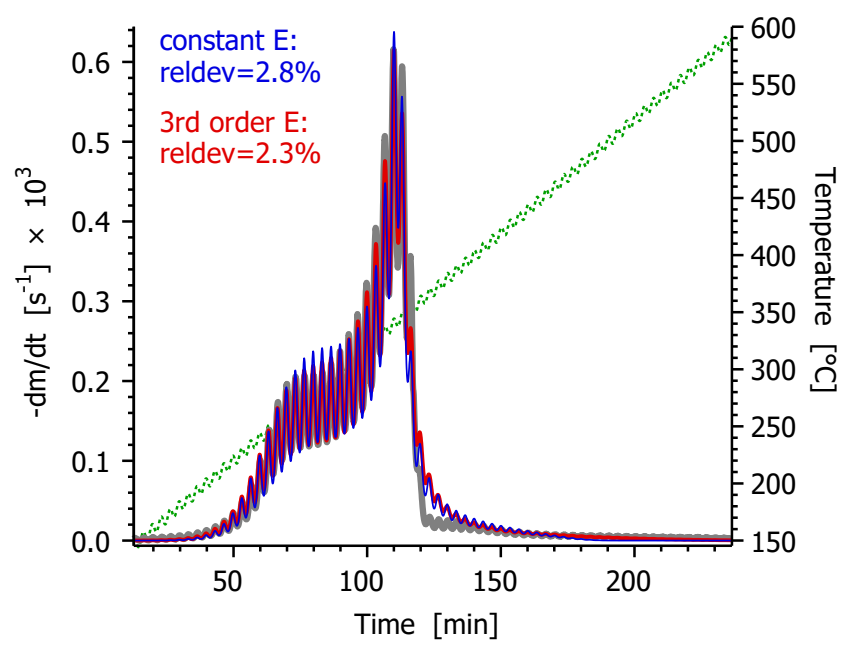

(h) Birch, modulated $T(t)$

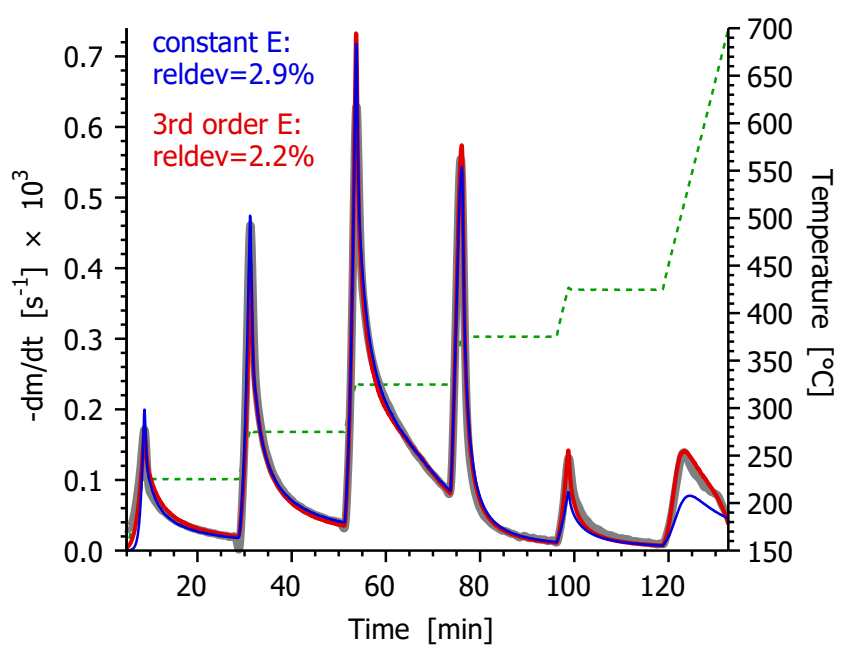

(j) Spruce bark, stepwise $T(t)$

Figure 2. Illustration of the fit quality when $E$ is constant (blue color), and $E$ is a third order polynomial of $\alpha$ (red color). $\tilde{A}(\alpha)$ was approximated by fifth order polynomials. The thick gray lines represent the experimental curves. The temperature programs, when present, are shown by thin, dashed green lines. Note that the same experimental curves were presented with other type of modelling in the works of Mészáros et al. 2004; ${ }^{12}$ (a, b); Becidan et al. 2007; ${ }^{13}$ (c, d); Várhegyi et al. 2011; ${ }^{14}$ (e, f); Tapasvi et al., $2013 ;^{16}(\mathbf{g}, \mathbf{h})$, and Barta-Rajnai et al. $2017 ;^{17}(\mathbf{i}, \mathbf{j})$.

This approximation can be recommended for complex modelling tasks because it can be solved numerically by high-speed algorithms with relatively easy computer programming. For this purpose the obtained $A(\alpha) f(\alpha)$ function can be factored into a constant $A$ and an $f(\alpha)$ part. The uniqueness of the factorizing can be ensured by a normalization so that the maximum of $f(\alpha)$ would be 1 . (This sort of normalization has been employed for other empirical $f(\alpha)$ functions, too. ${ }^{11}$ ) In this way the kinetic equation has the form of eq 1 and can be solved numerically by separating the variables:

$$
\int_{0}^{\alpha} \frac{d \alpha}{f(\alpha)}=A \int_{0}^{t} \exp \left(-\frac{E}{R T}\right) d t
$$

The left-hand-side is usually denoted by $g(\alpha)$. No analytical approximations are available for the present $g(\alpha)$ or for its inverse function. However, one can calculate numerically a few thousand values for this 
integral and store them together with the corresponding $\alpha$ and $f(\alpha)$ values in arrays for the modelling work. (The search in a sorted array is very fast. At each right-hand-side value arising in the work the software can search for the nearest $g(\alpha)$ in the array and the $\alpha$ and $f(\alpha)$ values stored with it.) The right-hand-side contains the well-known exponential integral at constant heating rates or at $T(t)$ programs consisting of linear sections. In such cases one of the widely used approximate formulas can be employed. Otherwise quadrature formulas can be recommended.

Compared to the one-step kinetic models of the literature, the present empirical model variant has an advantage: it can describe the pyrolysis at a wide range of $\mathrm{T}(\mathrm{t})$ functions with a given set of model parameters. Among others it could reasonably approximate the TGA experiments from the work of Tapasvi et al. ${ }^{16}$ at the $\mathrm{T}(\mathrm{t})$ programs shown in Figure 1. (The Supporting Information contains ten figures on the fit quality for these samples.)

\subsection{The Shape of the Employed Empirical Functions and the Fit Quality for 16 Biomass Samples.}

The $E$ vs $\alpha$ dependences and the shape of the $A(\alpha) f(\alpha)$ functions are shown in Figure 3 for the five biomasses presented in Figure 2. Figures $3 \mathrm{a}$ and $3 \mathrm{~b}$ visualize the spread of the $E$ values. The constant $E$ values scatter in a narrow interval while the variation of the approximated by $3^{\text {rd }}$ order polynomials results in a much wider range of $E$ values. It may be interesting to observe that the $E(\alpha)$ of the two woody biomasses, denoted by dashed lines in Figure 3, tend to low $E$ values at high $\alpha$ values while the other three biomasses had high $E$ values around $\alpha=1$. We have no reason to assume a physical reality behind this behavior, it may be just two different ways to describe formally the flat tailing sections of the $-d m^{\text {exp }} / d t$ curves of the biomass materials. The corresponding $A(\alpha) f(\alpha)$ functions also show different behaviors for the dashed and the solid lines in Figure $3 \mathrm{~d}$; this may be connected to the well-known compensation effect between $A$ and $E$ : an increase in $\mathrm{E}$ induces a rise in $A$.

Table 2 displays more details on the evaluation of the biomasses. The results with the $3^{\text {rd }}$ order $E(\alpha)$ polynomials were characterized by the mean $E$ values and by the $E$ values at the end of the domain, $E_{\alpha=1}$. $E_{\alpha=1}<100 \mathrm{~kJ} / \mathrm{mol}$ values appeared mainly at the wood samples. The exceptions are the spruce and its bark in the last two rows. On the other hand, the sorghum sample also exhibited low $E_{\alpha=1}$. These observations support the view that the isoconversional kinetics provides only formal approximations for biomass pyrolysis.

The lowest fit quality was obtained for the brewer spent grains and birch samples at constant $E$ : reldev $v_{5}=5.28 \%$ and reldev $=5.17 \%$, respectively. Both samples are shown in Figure 2 . The Supporting Information contains further figures on the fit quality of these samples. As these plots show, the fit quality is reasonable for these samples, too. 

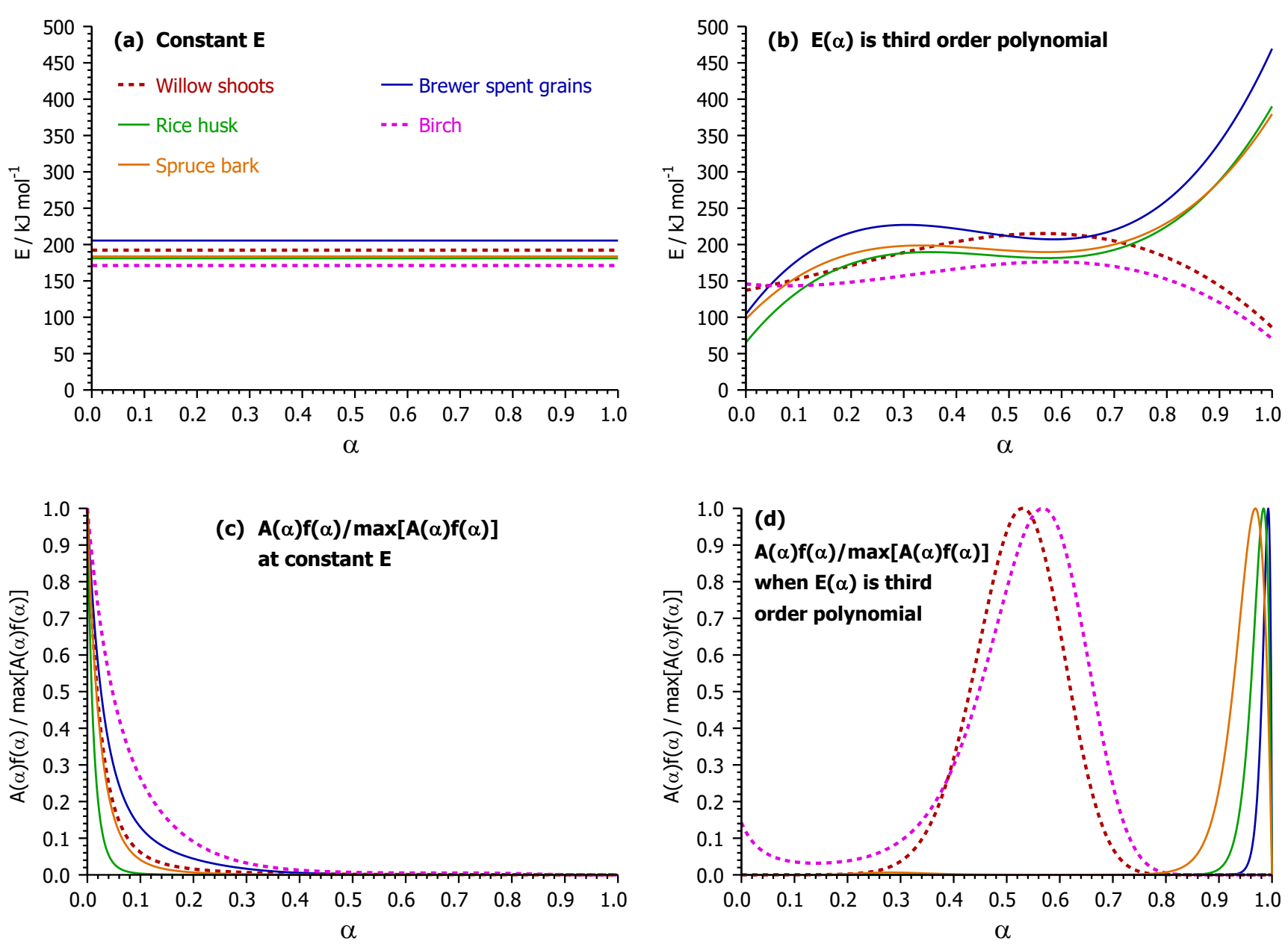

Figure 3. The $E(\alpha)$ and $A(\alpha) f(\alpha)$ functions for the five biomasses presented in Figure 2 at constant $E$ $(\mathrm{a}, \mathrm{c})$; and at $E(\alpha)$ functions approximated by $3^{\text {rd }}$ order polynomials. (The color codes and line types are presented in panel (a); their listing follows the order of Figure 2.)

Table 2. Evaluations of 16 Biomass Samples by Two Selected Model Variants ${ }^{\text {a,b }}$

\begin{tabular}{|c|c|c|c|c|c|c|c|}
\hline \multirow{2}{*}{$\begin{array}{l}\text { Source of } \\
\text { the experi- } \\
\text { ments }\end{array}$} & \multirow[t]{2}{*}{$\begin{array}{l}\text { Temperature } \\
\text { programs }\end{array}$} & \multirow[t]{2}{*}{ Biomass } & \multicolumn{2}{|c|}{$E$ is constant } & \multicolumn{3}{|c|}{$\begin{array}{c}E \text { is 3rd order } \\
\text { polynomial of } \alpha\end{array}$} \\
\hline & & & reldev $v_{\mathrm{N}}$ & E & reldev $v_{\mathrm{N}}$ & $E_{\text {mean }}$ & $E_{\alpha=1}$ \\
\hline \multirow{3}{*}{$\begin{array}{l}\text { Mészáros } \\
\text { et al. } \\
2004^{12}\end{array}$} & 10,20 and 40 & Black locust shoots & 3.11 & 201 & 2.65 & 178 & 71 \\
\hline & ${ }^{\circ} \mathrm{C} / \mathrm{min}$ & Poplar shoots & 3.78 & 207 & 3.13 & 187 & 68 \\
\hline & Stepwise $T(t)$ & Willow shoots & 3.42 & 192 & 2.74 & 179 & 86 \\
\hline \multirow{5}{*}{$\begin{array}{l}\text { Becidan et } \\
\text { al. } 2007^{13}\end{array}$} & 5,10 and 20 & Brewer spent grains & 5.28 & 206 & 3.94 & 237 & 469 \\
\hline & ${ }^{\circ} \mathrm{C} / \mathrm{min}$ & Coffee waste & 3.76 & 206 & 2.65 & 223 & 343 \\
\hline & $\begin{array}{l}\text { CRR } T(t) \\
\text { Stepwise } T(t)\end{array}$ & $\begin{array}{l}\text { Medium-density } \\
\text { fiberboard }\end{array}$ & 3.56 & 179 & 3.08 & 167 & 99 \\
\hline & & Corn stalk & 2.99 & 188 & 1.83 & 189 & 300 \\
\hline & & Rice husk & 3.54 & 181 & 2.17 & 198 & 390 \\
\hline
\end{tabular}




\begin{tabular}{|c|c|c|c|c|c|c|c|}
\hline & 4 and 40 & Sorghum & 2.49 & 188 & 2.23 & 165 & 63 \\
\hline $\begin{array}{l}\text { varnegyi } \\
\text { et al. } \\
2011^{14}\end{array}$ & $\begin{array}{l}{ }^{\circ} \mathrm{C} / \mathrm{min} ; \\
\text { Two stepwise } \\
T(t) \text { programs. }\end{array}$ & Wheat straw & 1.76 & 188 & 1.60 & 188 & 229 \\
\hline Trninić et & 5,10 and 20 & Corncob (Hawaii) & 3.09 & 185 & 2.44 & 183 & 248 \\
\hline al. $2012^{15}$ & $\begin{array}{l}{ }^{\circ} \mathrm{C} / \mathrm{min} ; \\
\text { Stepwise } T(t)\end{array}$ & Corncob (Serbia) & 2.21 & 187 & 2.17 & 194 & 252 \\
\hline $\begin{array}{l}\text { Tapasvi et } \\
\text { al., } 2013^{16}\end{array}$ & $\begin{array}{l}5,10,20 \text { and } 40 \\
{ }^{\circ} \mathrm{C} / \mathrm{min} ; \mathrm{CRR}\end{array}$ & Birch & 5.17 & 171 & 3.43 & 152 & 71 \\
\hline & $\begin{array}{l}T(t) ; \text { Modulated } \\
T(t) ; \text { Stepwise } \\
T(t) ; \text { Two } \\
\text { isothermal } T(t) \\
\text { programs. }\end{array}$ & Spruce & 3.51 & 168 & 3.30 & 161 & 139 \\
\hline Barta- & $2.5,10$ and 40 & Bark of spruce & 3.33 & 184 & 2.18 & 207 & 380 \\
\hline $\begin{array}{l}\text { Rajnai et } \\
\text { al. } 2017^{17}\end{array}$ & $\begin{array}{l}{ }^{\circ} \mathrm{C} / \mathrm{min} ; 2 \\
\text { stepwise and } 3 \\
\text { isothermal } T(t)\end{array}$ & Spruce & 4.43 & 174 & 4.26 & 186 & 260 \\
\hline
\end{tabular}

4.4. Restricting the Evaluations to Constant Heating Rate Experiments. As mentioned in the Introduction, almost all isoconversional kinetic studies were based only on constant heating rate experiments. Herewith we examine this approach from the aspects of the present work. In Tables 1 and 2 there was at least one experiment with nonlinear $T(t)$ for each sample. Table 3 shows the evaluations that were carried out only on the constant heating rate experiments. Here three ways were used for the determination of the $c$ factors (as shown in Subsection 3.3), while the order of polynomials for $E(\alpha)$ varied from 0 to 3 . The evaluations were based on 46 constant heating rate experiments that were available for the 16 biomass samples, hence Table 3 was based on $3 \times 4 \times 16$ evaluations.

It turned out that the model variants with constant $E$ gave better fit qualities (lower reldev 46 values) for the subset of the constant heating rate experiments than the third order polynomials for all available experiments (reldev 85 ) in Table 2. Accordingly we do not need variable $E(\alpha)$ functions if the aim of the modelling is to describe only constant heating rate experiments.

The parameters obtained from the constant heating rate experiments can provide some rough predictions for the remaining 39 experiments with nonlinear $\mathrm{T}(\mathrm{t})$, as the corresponding reldev 39 values shows in the table. From this respect the prediction power of the constant $E$ model is close to those of the $E(\alpha)$ model variants. 
Table 3. Evaluations of the Constant Heating Rate Experiments Only ${ }^{\text {a,b }}$

\begin{tabular}{|c|c|c|c|c|c|}
\hline \multicolumn{2}{|c|}{ Order of polynomials for $E$} & \multirow{2}{*}{$\frac{0}{2.70}$} & \multirow{2}{*}{$\frac{1}{2.56}$} & \multirow{2}{*}{$\frac{2}{2.43}$} & \multirow{2}{*}{$\frac{3}{2.23}$} \\
\hline Separate $c_{\mathrm{i}}$ for each & fit (reldev46) & & & & \\
\hline experiment & predictions & 5.95 & 6.12 & 5.61 & 5.71 \\
\hline & $\left(\right.$ reldev $\left._{39}\right)$ & & & & \\
\hline & mean $E$ & 203 & 207 & 190 & 191 \\
\hline & lowest $\mathrm{E}$ & 172 & 126 & -56 & -492 \\
\hline & highest E & 261 & 410 & 478 & 645 \\
\hline \multirow{6}{*}{$\begin{array}{l}\text { Common } c \text { for the } \\
\text { experiments of a } \\
\text { sample }\end{array}$} & reldev 46 & 2.77 & 2.61 & 2.48 & 2.27 \\
\hline & predictions & 6.29 & 6.42 & 6.19 & 6.13 \\
\hline & $($ reldev39) & & & & \\
\hline & mean $E$ & 203 & 207 & 191 & 192 \\
\hline & lowest $\mathrm{E}$ & 172 & 139 & 24 & -478 \\
\hline & highest E & 261 & 408 & 478 & 648 \\
\hline \multirow{6}{*}{$\begin{array}{l}c_{\mathrm{i}} \text { were approximated } \\
\text { by mass loss values }\end{array}$} & reldev 46 & 2.85 & 2.74 & 2.56 & 2.33 \\
\hline & predictions & 6.01 & 6.16 & 5.99 & 5.93 \\
\hline & (reldev39) & & & & \\
\hline & mean $E$ & 203 & 207 & 191 & 193 \\
\hline & lowest E & 172 & 144 & 82 & 19 \\
\hline & highest E & 262 & 383 & 411 & 669 \\
\hline
\end{tabular}

\footnotetext{
${ }^{a}$ The constant heating rate experiments were evaluated in different ways for the 16 biomass samples. reldev ${ }_{46}$ is the root mean square relative deviation calculated for all constant heating rate $-d m^{\mathrm{obs}} / d t$ curves. reldev 39 characterizes how the obtained models can predict the 39 experiments with nonlinear $T(t)$. ${ }^{\mathbf{b}}$ The dimensions of $E$, reldev ${ }_{46}$ and reldev 39 are $\mathrm{kJ} / \mathrm{mol}$ and $\%$.
}

4.5. Realistic and Unrealistic $\boldsymbol{E}$ values. As Table 3 shows, the evaluation of the constant heating rate experiments resulted in highly negative $E_{\alpha=1}$ values when third order polynomials were used for $E(\alpha)$, and the $c$ scale factors were determined by the first and second methods of Subsection 3.3. There were no negative $E$ values when the $c$ factors were approximated by the third way of Subsection 3.3 and the model contained only 10 parameters ( 4 coefficients for $E(\alpha)$ and 6 coefficients for $\ln \tilde{A}(\alpha)$ ). However, unrealistic $E$ values appeared in this case, too. Positive, but unrealistically low $E$ values were obtained at four of the 16 biomass samples then. The highest $E$ value in this group, $669 \mathrm{~kJ} / \mathrm{mol}$, also appear to be unrealistic. At this point we should clarify the term "unrealistic". One can start from the IUPAC definition of the activation energy: "An empirical parameter characterizing the exponential temperature dependence of the rate coefficient". ${ }^{28}$ Therefore we may expect that even an empirical model should give realistic temperature dependences for the reaction rate at any $\alpha$ value. The activation energy values $19 \mathrm{~kJ} / \mathrm{mol}$ and $669 \mathrm{~kJ} / \mathrm{mol}$ in Table 2 would correspond to rather unusual temperature dependences at $600^{\circ} \mathrm{C}$ : an increase from $600^{\circ} \mathrm{C}$ 
to $915^{\circ} \mathrm{C}$ doubles only the reaction rate at $E=19 \mathrm{~kJ} / \mathrm{mol}$, while a step from $600^{\circ} \mathrm{C}$ to $650^{\circ} \mathrm{C}$ increases the reaction rate by a factor of 150 at $E=699 \mathrm{~kJ} / \mathrm{mol}$. Such temperature dependences do not occur in the thermal analysis of biomass samples in the kinetic regime. Accordingly one should choose a model variant with less than ten parameters if the evaluation is based only on constant heating rate experiments.

The above observations indicate a particularly strong compensation effect between $\mathrm{E}(\alpha)$ and $\mathrm{A}(\alpha) \mathrm{f}(\alpha)$ in eq 2. As mentioned above, $E(\alpha)$ and $A(\alpha) f(\alpha)$ can be arbitrary functions which may have any positive values in the domain $0 \leq \alpha<1$. The test calculations of this work indicated that an arbitrary $A(\alpha) f(\alpha)$ can compensate even the negative $E$ values without a worsening of the fit quality.

\section{LEAST SQUARES CURVE FITTING FOR $\alpha^{\mathrm{obs}}$ AND $d \alpha^{\mathrm{obs}} / d t$}

5.1 Evaluation of $\alpha^{\text {obs }}$ values. The literature of the "model-free" evaluations is based on parameter determinations either from $\alpha^{\text {obs }}$ values, or from $\alpha^{\text {obs }}$ and $d \alpha^{\text {obs }} / d t$ values. ${ }^{1,3,4}$ The present section deals with the least squares evaluation of these experimental quantities. As mentioned above, the experimental reacted fraction can only be determined approximately for biomass samples because part of the pyrolysis reactions overlap with the carbonization of the formed char. An alternative would be the modeling of the whole thermal decomposition, pyrolysis and char carbonization together, but the latter process lasts until very high temperatures. $^{27}$

Table 4. Least squares evaluation of $\alpha^{\exp }$ and $d \alpha^{\exp } / d t^{\text {a,b }}$

\begin{tabular}{|c|c|c|c|c|}
\hline \multicolumn{2}{|l|}{ Sample } & \multirow{2}{*}{$\begin{array}{c}\mathbf{B} \\
192\end{array}$} & \multirow{2}{*}{$\begin{array}{c}\mathbf{P} \\
213\end{array}$} & \multirow{3}{*}{$\begin{array}{c}\mathbf{W} \\
197\end{array}$} \\
\hline Constant $E$; evaluation of & $E$ & & & \\
\hline$\alpha^{\exp }$ & reldev 4 & 1.05 & 1.48 & \\
\hline \multirow{4}{*}{$\begin{array}{l}E \text { is } 3 \text { rd order polynomial; } \\
\text { evaluation of } \alpha^{\exp }\end{array}$} & mean $E$ & 189 & 211 & 196 \\
\hline & lowest $E$ & 161 & 155 & 182 \\
\hline & highest $E$ & 202 & 227 & 204 \\
\hline & reldev 4 & 0.97 & 1.45 & 1.05 \\
\hline \multirow{2}{*}{$\begin{array}{l}\text { Constant } E \text {; evaluation of } \\
d \alpha^{\exp } / d t\end{array}$} & $E$ & 197 & 207 & 193 \\
\hline & reldev 4 & 3.26 & 3.79 & 3.39 \\
\hline \multirow{4}{*}{$\begin{array}{l}E \text { is } 3^{\text {rd }} \text { order polynomial; } \\
\text { evaluation of } d \alpha^{\exp } / d t\end{array}$} & mean $E$ & 179 & 189 & 181 \\
\hline & lowest $E$ & 70 & 78 & 89 \\
\hline & highest $E$ & 216 & 229 & 215 \\
\hline & reldev 4 & 2.62 & 3.15 & 2.74 \\
\hline
\end{tabular}


The biomass samples from the work of Mészáros et al. ${ }^{12}$ were selected for test evaluations in this section. The reacted fraction was approximated as

$$
\alpha^{o b s}(t) \cong \frac{m_{150^{\circ} \mathrm{C}}^{o b s}-m^{o b s}(t)}{m_{150^{\circ} \mathrm{C}}^{o b}-m_{600^{\circ} \mathrm{C}}^{o b s}}
$$

Here the starting point was selected to be $150^{\circ} \mathrm{C}$, which is after the drying of the sample and before the start of the thermal decomposition. The selected final point, $600^{\circ} \mathrm{C}$ is a compromise: the reaction rate is already low there while the long, flat, featureless tailing is not overemphasized in the domain of evaluation. (See Figure $2 \mathrm{a}-2 \mathrm{~b}$ and the figures on these samples in the Supporting Information.) When $\alpha^{\text {obs }}$ is evaluated, the objective function, eq 3, and the formula for the relative deviation, eq 6 , are written for $\alpha^{\text {obs }}$ and $\alpha^{\text {calc }}$.

The results are summarized in Table 4. The evaluation of the $\alpha^{\exp }$ values by constant $E$ and by third order polynomials for $E(\alpha)$ gave nearly identical fit qualities. The differences in reldev 4 are 0.08 for the black locust and only 0.03 for the other two samples. These data suggest that there is no need for a variable $E$ when the investigators are interested in the modelling of $\alpha^{\text {obs }}$ only. The parameters derived from the $\alpha^{\text {obs }}$ values provide some rough approximations for the $d \alpha^{\mathrm{obs}} / d t$ curves, too, as shown in Figure 4 . There are no substantial differences between the constant $E$ and the $3^{\text {rd }}$ order $E(\alpha)$ models from this aspect. Figure 4 illustrates the fit qualities obtained by the constant $E$ model.
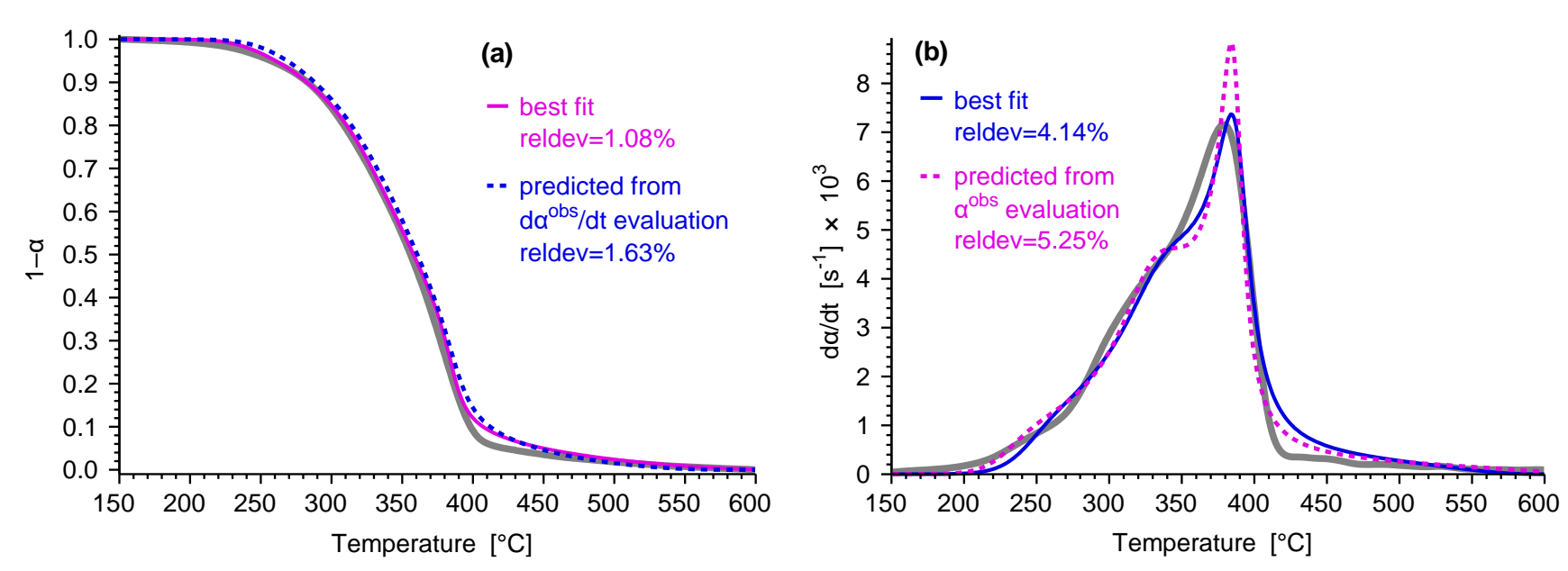

Figure 4. Fit qualities for the $40^{\circ} \mathrm{C} / \mathrm{min}$ experiment on the willow shoots sample. The constant $E$ model was employed for the least squares evaluation of $\alpha^{\mathrm{obs}}(\mathbf{a})$, and $d \alpha^{\mathrm{obs}} / d t$ (b). The experimental data are shown by thick gray line. The best fitting and the predicted curves are denoted by solid and dashed lines, respectively. The magenta and the blue colors correspond to the evaluation of the $\alpha^{\text {obs }}$ and $d \alpha^{\text {obs }} / d t$ data.

5.2 Evaluation of the $\boldsymbol{d} \boldsymbol{\alpha}^{\text {obs }} / \boldsymbol{d} \boldsymbol{t}$ curves. The differentiation of eq 17 with respect to time yields eq 14 with the $c$ constants by method (3) of subsection 3.3. Accordingly the results of this evaluation are similar to the results presented in Section 4. Figure 4a illustrate that the parameters obtained from the $d \alpha^{\mathrm{obs}} / d t$ curves are suitable for an approximate description of the $\alpha^{\text {obs }}$ data, too. 


\section{CONCLUSIONS}

(1) The $E(\alpha)$ and $A(\alpha) f(\alpha)$ functions of the isoconversional ("model-free") evaluation were approximated by simple, versatile formulas. The corresponding parameters were determined by the method of least squares by finding the best fit for the experimental data, $-d m^{\mathrm{obs}} / d t$ or $\alpha^{o b s}(t)$.

(2) To provide a sound basis for the work, the evaluations with the various model variants were carried out on 85 thermogravimetric experiments which had been published earlier with different types of kinetic modelling. The experiments belonged to 16 biomass samples including woody biomass, agricultural residues and industrial wastes and were performed at a variety of linear and non-linear temperature programs.

(3) Ten kinetic parameters and one or more scale factors provided good fit with reasonable $E$ values for the experimental $-d m / d t$ data. In this model variant $E(\alpha)$ was approximated by third order polynomials and the prefactor part of the kinetic equation, $A(\alpha) f(\alpha)$, was approximated by an empirical formula with six adjustable parameters. When the model contained more parameters, the evaluation proved to be illconditioned. Quite different kinetic parameters could provide similar fit qualities in such cases while the $E(\alpha)$ functions exhibited meaningless $E$ values in the vicinity of $\alpha=1$.

(4) A model with constant $E$ values provided acceptable fit qualities in all tested cases. Here again $A(\alpha) f(\alpha)$ was described by an empirical formula with six parameters. This empirical model allows fast numerical solutions that may be helpful in complex multidimensional modellings. Compared to the onestep kinetic models of the literature, the presented empirical model with constant $E$ has an advantage: it can describe the pyrolysis at a wide range of $\mathrm{T}(\mathrm{t})$ functions with a given set of model parameters. Among others it could reasonably approximate the TGA experiments performed with the T(t) programs in Figure 1.

(5) When the evaluation was restricted to the constant heating rate experiments, the model variants with constant $E$ or with first and second order $E(\alpha)$ polynomials provided good fit qualities. This subset of the experiments could not provide enough experimental information for a meaningful evaluation by third order $E(\alpha)$ polynomials.

(6) When the $\alpha^{o b s}$ data were evaluated instead of the $-d m^{\text {obs }} / d t$ curves, the model variants with constant $E$ and third order $E(\alpha)$ polynomials provided nearly the same fit qualities. One should note here that the $-d m^{\text {obs }} / d t$ curves are known to be more characteristic to the peculiarities of the biomass pyrolysis than the integral curves ( $m^{\text {obs }}$ or $\alpha^{o b s}$ ). If the investigations are restricted to the integral curves, then the model variant with constant $E$ is adequate.

(7) The results suggest that the kinetic equations with variable $E$ and $A$ are ill-conditioned due to the compensation effect between $E(\alpha)$ and $A(\alpha) f(\alpha)$. The compensation effects between the constant $E$ and $A$ values are well-known, and the problems are more serious when $E$ and $A$ are arbitrary functions of $\alpha$.

(8) Transparent ways are needed to choose reasonable approximations from the infinite number of solutions that can give good fit for the experiments. In the present work the order of the polynomials for $E(\alpha)$ was decreased to third order or below while the corresponding changes in the fit quality were carefully checked. 


\section{ASSOCIATED CONTENT \\ Supporting Information}

The Supporting Information is available free of charge on the ACS Publications website at DOI 10.1021/acs.energyfuels.9b00040

The obtained parameters are presented together with figures on $E(\alpha), A(\alpha) f(\alpha)$ and the fit quality for 16 biomass samples at two model variants.

\section{AUTHOR INFORMATION}

\section{Corresponding Author}

* To whom correspondence should be addressed.

Email: varhegyi.gabor@t-online.hu or gvarhegyi@gmail.com

tel. +36 1 2461894. ORCID: http://orcid.org/0000-0002-2933-1845

\section{ACKNOWLEDGMENTS}

The author is grateful to his coworkers in those earlier works which provided the data for the present test evaluations, ${ }^{12-17}$ with special thanks to Erika Mészáros, Emma Jakab, Michaël Becidan, Marta Trninić, Liang Wang, Dhruv Tapasvi, Roger Khalil, Morten Grønli, Øyvind Skreiberg, Eszter Barta-Rajnai and Zsuzsanna Czégény. The author acknowledges the financial support for the previous years by the Research Council of Norway and a number of industrial partners through the project BioCarb+ ("Enabling the Biocarbon Value Chain for Energy").

\section{NOMENCLATURE}

$\alpha=$ reacted fraction [dimensionless]

$A=$ pre-exponential factor $\left[\mathrm{s}^{-1}\right]$

$\tilde{A}(\alpha)=A(\alpha) f(\alpha) /(1-\alpha)$ at $\alpha<1 \quad\left[\mathrm{~s}^{-1}\right]$

$a, \bar{a}, b, \bar{b}=$ coefficients in the polynomial approximations of $E(\alpha)$ and $\ln \tilde{A}(\alpha) \quad\left[\mathrm{kJ} / \mathrm{mol}, \operatorname{ln~s}{ }^{-1}\right]$

$E=$ activation energy $[\mathrm{kJ} / \mathrm{mol}]$

$f(\alpha)=$ empirical function expressing the change of the reactivity as the reactions proceed [dimensionless]

$g(\alpha)=$ the integral of $1 / f(\alpha)$ in eq 16 [dimensionless]

$h_{\mathrm{j}}=$ height of an experimental $-\mathrm{d} m / \mathrm{d} t$ curve $\left[\mathrm{s}^{-1}\right]$

$m=$ the mass of the sample normalized by the initial dry sample mass [dimensionless]

of $=$ objective function minimized in the least squares evaluation [dimensionless]

$N_{\text {exper }}=$ number of the experiments evaluated together by the method of least squares

$N_{\mathrm{j}}=$ number of the evaluated data on the $j$ th experimental curve

$R=$ gas constant $\left(8.3143 \times 10^{-3} \mathrm{~kJ} \mathrm{~mol}^{-1} \mathrm{~K}^{-1}\right)$

reldev $=$ the deviation between the observed and calculated data expressed as per cent of the corresponding peak height $[\%]$

reldev $85=$ root mean square of the reldev values of 85 experiments [\%]

$t=$ time $[\mathrm{s}]$

$T=$ temperature $\left[{ }^{\circ} \mathrm{C}, \mathrm{K}\right]$ 
$T_{1}(x) \ldots T_{5}(x)=$ Chebyshev polynomials of the first kind

$x=2 \alpha-1 \quad$ [dimensionless]

Subscripts:

$i=$ digitized point on an experimental curve

$j=$ experiment

\section{REFERENCES}

1. Vyazovkin, S.; Burnham, A.K.; Criado, J.M.; Pérez-Maqueda, L.A.; Popescu, C.; Sbirrazzuoli, N. ICTAC Kinetics Committee recommendations for performing kinetic computations on thermal analysis data. Thermochim. Acta, 2011, 520, 1-19.

2. Retrieved from the Web of Science database, https://apps.webofknowledge.com/, December 20, 2018.

3. Antal Jr, M.J.; Friedman, H.L.; Rogers, F.E. Kinetics of cellulose pyrolysis in nitrogen and steam. Combustion Sci. Technol., 1980, 21, 141-152.

4. Cai; J., Xu, D.; Dong, Z.; Yu, X.; Yang, Y.; Banks, S.W.; Bridgwater, A.V. Processing thermogravimetric analysis data for isoconversional kinetic analysis of lignocellulosic biomass pyrolysis: Case study of corn stalk. Renew. Sustain. Energy Reviews, 2018, 82, 2705-2715.

5. Samuelsson, L.N.; Babler, M.U.; Moriana, R. A single model-free rate expression describing both nonisothermal and isothermal pyrolysis of Norway Spruce. Fuel, 2015, 161, 59-67.

6. Samuelsson, L.N.; Babler, M.U.; Brännvall, E.; Moriana, R.; Pyrolysis of kraft pulp and black liquor precipitates derived from spruce: thermal and kinetic analysis. Fuel Process. Technol., 2016, 149, 275-284.

7. Samuelsson, L.N.; Umeki, K.; Babler, M.U. Mass loss rates for wood chips at isothermal pyrolysis conditions: A comparison with low heating rate powder data. Fuel Process. Technol., 2017, 158, $26-34$.

8. Sadegh-Vaziri, R.; Babler, M.U. Modeling of slow pyrolysis of various biomass feedstock in a rotary drum using TGA data. Chem. Eng. Process. - Process Intensif., 2018, 129, 95-102.

9. Carrier, M.; Auret, L.; Bridgwater, A.; Knoetze, J.H., Using apparent activation energy as a reactivity criterion for biomass pyrolysis. Energy Fuels, 2016, 30, 7834-7841.

10. Naqvi, S.R.; Tariq, R.; Hameed, Z.; Ali, I.; Taqvi, S.A.; Naqvi, M.; Niazi, M.B.K.; Noor, T.; Farooq, W. Pyrolysis of high-ash sewage sludge: Thermo-kinetic study using TGA and artificial neural networks. Fuel, 2018, 233, 529-538.

11. Várhegyi, G.; Szabó, P.; Jakab, E.; Till, F.; Richard J-R. Mathematical modeling of char reactivity in Ar-O ${ }_{2}$ and $\mathrm{CO}_{2}-\mathrm{O}_{2}$ mixtures. Energy Fuels 1996, 10, 1208-1214.

12. Mészáros, E.; Várhegyi, G.; Jakab, E.; Marosvölgyi, B. Thermogravimetric and reaction kinetic analysis of biomass samples from an energy plantation. Energy Fuels 2004, 18, 497-507.

13. Becidan, M.; Várhegyi, G.; Hustad, J. E.; Skreiberg, Ø. Thermal decomposition of biomass wastes. A kinetic study. Ind. Eng. Chem. Res. 2007, 46, 2428-2437.

14. Várhegyi, G.; Bobály, B.; Jakab, E.; Chen, H. Thermogravimetric study of biomass pyrolysis kinetics. A distributed activation energy model with prediction tests. Energy Fuels, 2011, 25, 24-32.

15. Trninić, M.; Wang, L.; Várhegyi, G.; Grønli, M.; Skreiberg, Ø. Kinetics of corncob pyrolysis. Energy Fuels, 2012, 26, 2005-2013. 
16. Tapasvi, D.; Khalil, R.; Várhegyi, G.; Tran, K.-Q.; Grønli, M.; Skreiberg, Ø. Thermal decomposition kinetics of woods with an emphasis on torrefaction. Energy Fuels 2013, 27, 6134-6145.

17. Barta-Rajnai, E.; Várhegyi, G.; Wang, L.; Skreiberg, Ø.; Grønli, M.; Czégény, Zs. Thermal decomposition kinetics of wood and bark and their torrefied products. Energy Fuels 2017, 31, 4024-4034.

18. Brachi, P.; Miccio, F.; Miccio, M.; Ruoppolo, G. Isoconversional kinetic analysis of olive pomace decomposition under torrefaction operating conditions. Fuel Process. Technol.; 2015, 130, 147-154.

19. Sriram, A.; Swaminathan, G. Pyrolysis of Musa balbisiana flower petal using thermogravimetric studies. Bioresource technology. 2018, 265, 236-246.

20. Várhegyi, G.; Antal, M. J., Jr.; Székely, T.; Szabó, P. Kinetics of the thermal decomposition of cellulose, hemicellulose and sugar cane bagasse. Energy Fuels 1989, 3, 329-335.

21. Várhegyi, G.; Szabó, P.; Mok, W. S. L.; Antal, M. J., Jr. Kinetics of the thermal decomposition of cellulose in sealed vessels at elevated pressures. Effects of the presence of water on the reaction mechanism. J. Anal. Appl. Pyrolysis 1993, 26, 159-174.

22. Várhegyi, G.; Chen, H.; Godoy, S. Thermal decomposition of wheat, oat, barley and Brassica carinata straws. A kinetic study. Energy Fuels 2009, 23, 646-652.

23. Press, W. H.; Flannery, B. P.; Teukolsky, S. A.; Vetterling, W. T. Numerical Recipes. The Art of Scientific Computing. 2nd ed., Cambridge University Press, Cambridge (U.K.), 1992.

24. Kolda, T. G.; Lewis, R. M.; Torczon, V. Optimization by direct search: New perspectives on some classical and modern methods. SIAM Rev. 2003, 45, 385-482.

25. De Boor, C. A practical guide to splines, revised Edition, Vol. 27 of Applied Mathematical Sciences, Springer, New York, 2001.

26. Várhegyi, G.; Jakab, E.; Antal, M. J., Jr.: Is the Broido - Shafizadeh model for cellulose pyrolysis true? Energy Fuels 1994, 8, 1345-1352.

27. Antal, M. J.; Grønli, M. The art, science, and technology of charcoal production. Ind. Eng. Chem. Res. 2003, 42, 1619-1640.

28. Compendium of Chemical Terminology, Gold Book, version 2.3.3. International Union of Pure and Applied Chemistry, 2014, https://goldbook.iupac.org/pdf/goldbook.pdf 